\title{
Effect of different fat supplements on performance of dairy calves during cold season
}

\author{
E. Ghasemi, ${ }^{1}$ M. Azad-Shahraki, and M. Khorvash \\ Department of Animal Science, College of Agriculture, Isfahan University of Technology, Isfahan 84156-83111, I. R. Iran
}

\begin{abstract}
The objective of this experiment was to evaluate the effects of starter supplementation with fat sources differing in their fatty acid (FA) profile on performance of dairy calves during cold season. Sixty Holstein calves (3 d of age; $39.7 \pm 3.8 \mathrm{~kg}$ of body weight) were randomly assigned to 1 of 5 starter diets supplemented with (1) no fat or oil source (control), (2) $3 \%$ palm fat (PLF), (3) $3 \%$ soybean oil (SBO), (4) $3 \%$ tallow (TAL), and (5) a $3.2 \%$ mixture (MIX) of PLF, SBO, and fish oil. The fat supplements were substituted for corn in the basal starter diet. Both the control and fat-supplemented diets contained similar amounts of dietary crude protein (19.4\%), but the latter had a slightly higher quantity of calculated metabolizable energy (3.17 vs. $3.07 \mathrm{Mcal} /$ $\mathrm{kg}$ ) than did the former. Calves were reared outdoor in individual pens during the cold of winter with a mean ambient temperature of $5.0^{\circ} \mathrm{C}$ during the study period. Whole milk was offered twice daily from d 3 to 45 and once from d 46 to 49 . The animals were weaned on $\mathrm{d}$ 50 and monitored in their individual pens until d 70 . Supplementation with SBO and MIX increased both the dietary concentration and ratio of essential FA (n-6 and n-3), whereas supplementation with TAL and PLF made no change in the essential FA profile. Starter intake and average daily gain were not affected by PLF and TAL supplements, but were reduced as a result of feeding MIX. Feeding supplemental SBO did not affect starter intake, but tended to improve average daily gain and final body weight. Fat sources had no effects on body skeletal measurements, fecal score, digestibility, ruminal $\mathrm{pH}$, ammonia, and total volatile FA concentrations; however, feeding MIX increased rumen molar proportion of propionate. No differences were observed in blood metabolites across the treatments during the preweaning period. Plasma concentrations of triacylglycerol and cholesterol increased when fat sources
\end{abstract}

Received August 4, 2016.

Accepted March 27, 2017.

${ }^{1}$ Corresponding author: ghasemi@cc.iut.ac.ir were supplemented and glucose concentration increased when SBO was supplemented during the postweaning period. Overall, addition of $3 \%$ PLF or TAL to the diet of young calves failed to improve growth performance. Although addition of SBO and MIX increased the dietary essential FA concentration, calf performance was only improved when SBO was supplemented.

Key words: young calf, fatty acids, feed efficiency, cold season

\section{INTRODUCTION}

Recent studies have shown that intensified feeding of heifer calves during the preweaning period has a range of long-term positive effects including reduced age at conception and calving, increased BW at calving, and improved milk production (Gelsinger et al., 2016). The dairy industry has now progressively changed from a restricted allowance of about $4 \mathrm{~L} / \mathrm{d}$ of milk to more generous allowances $(6 \mathrm{~L} / \mathrm{d}$ or more), partly because of long-term performance (Bach, 2012). However, greater allowances might result in lower rates of rumen development and postweaning ADG by depressing starter intake (Davis and Drackley, 1998). Feeding extra energy as fat is another way to increase BW gain, as is feeding a high amount of liquid feed, especially during periods of subthermoneutral temperatures (Jaster et al., 1992). On the other hand, rearing young calves in outdoor facilities during the winter months increases the energy requirement due to cold stress. If calves are fed the same amounts of nutrients as under moderate environmental conditions, less energy will be available to support growth. Holt (2014) reported that calves raised in winter months consumed more calf starter than those born in other months, but had the same weight gains as other seasons. Limited data are available to evaluate the effect of supplemental fat in starter diets for young calves during cold stress. The addition of 5, 10, and $20 \%$ fat from Ca-soaps in starter diets linearly reduced both intake and ADG (Fallon et al., 1986). Hill et al. (2015) found that, compared with starters containing tallow or no fat, those including $2 \%$ soybean oil reduced calf starter intake and ADG. On the other hand, Araujo et 
al. (2014) reported that feeding a high-fat starter diet containing $11.2 \%$ fat accompanied by offering $6 \mathrm{~L} / \mathrm{d}$ of milk replacer resulted in increased overall $\mathrm{BW}$ and growth.

Various types of supplemental fat with different mixes of individual fatty acids (FA) have been fed to dairy cattle (NRC, 2001). However, NRC (2001) recommends a low fat level in calf starters $(\sim 3 \%)$, as feeding high-fat diets $(>6 \%)$ or fat feeding under normal weather conditions have been reported to cause negative effects on calf feed intake and growth (Fallon et al., 1986; Hill et al., 2015; Kazemi-Bonchenari et al., 2016). In addition to the utilization of FA as an energy source, certain FA (PUFA) are biologically active molecules. Linoleic (C18:2) and $\alpha$-linolenic (C18:3) acids, as well as the very long chain PUFA (i.e., C20:4n-6, C20:5n-3, and C22:6n-3), are essential for membrane fluidity and neural development and for the production of eicosanoids, which have numerous physiological and metabolic properties (Berg et al., 2002). However, no defined essential FA requirement exists for ruminants (Palmquist, 2010). Partially replacing coconut oil with porcine lard in milk replacer increased intake of linoleic and $\alpha$-linolenic acids and improved calf performance and some aspects of immunity (Garcia et al., 2014). Typical starter diets based on corn and soybean meal contain relatively low concentrations of $\mathrm{C} 18: 2$ and $\mathrm{C} 18: 3$, and are almost devoid of C20:4, C20:5, and C22:6 (Hill et al., 2009). Hill et al. (2011, 2015) observed that different FA supplementation in calf starter had different effects on calf intake, performance, and health status.

In the current study, we hypothesized that supplementation of starter diets with fat at the typical inclusion rate $(\sim 3 \%)$ during cold weather (which increases energy requirement) would not adversely affect feed intake, thereby improving energy intake and growth performance of young calves. Moreover, it is less clear whether different types of FA have differential effects on these responses. The objective of our study was to determine whether the intake of energy or FA with differences in their chain lengths, saturation, or chemical form (SFA, MUFA, PUFA, rumen inert, and unprotected FA) would have different effects on the performance of calves raised in winter.

\section{MATERIALS AND METHODS}

\section{Calves, Diets, and Management}

The experiment was conducted at the facilities of the dairy farm of FKA Animal Husbandry and Agriculture Co. (Isfahan, Iran), during the period from November 2014 to February 2015, the typical cold season in the region (Table 1). A total of 60 Holstein calves (35 females; 25 males) were separated from their dams (second parity or more) shortly after birth and fed $6 \mathrm{~L}$ of colostrum within the first $12 \mathrm{~h}$ of life $(3 \mathrm{~L}$ of colostrum within $2 \mathrm{~h}$ of life and $3 \mathrm{~L}$ in a second feeding). Calves were housed outdoors in $1 \times 2 \mathrm{~m}$ individual pens at ambient temperature. The interior of each pen was bedded with wood shavings, and replenished every 24 or 48 h. At d 3 of age, the calves $(39.7 \pm 3.8 \mathrm{~kg}$ of BW) were fed 1 of the following 5 diets: (1) a basal starter with no fat supplement (CON), (2) $3 \%$ of dietary DM as palm fat (PLF; Energizer RP-10, IFFCO, Johor, Malaysia), (3) $3 \%$ of dietary DM as soybean oil (SBO; Naz Industrial Vegetable Oil Co, Isfahan, Iran), (4) $3 \%$ of dietary DM as tallow (TAL; Lador Fat, Ala Roghan Sepahan Co. Isfahan, Iran), or (5) $3.2 \%$ of dietary DM as a mixture (MIX; 1:1:1.2, wt/wt) of PLF, SBO, and Ca salt of fish oil (StrataG, Virtus Nutrition, LLC, Corcoran, CA). Assuming that typical starter diets (based on corn grain and soybean meal) contain about $50 \%$ of their FA as linoleic acid and 3\% as $\alpha$-linolenic acid (n6:n-3 ratio >15; Hill et al., 2009), the MIX treatment was formulated with soybean and fish oils to provide an approximate n-6:n-3 ratio of $6: 1$, which is the optimum recommended level for human infants (Klein, 2002). The FA profiles of the supplemental fat sources were provided by the manufacturer (Table 2). The basal diet contained alfalfa hay, corn, barley, and soybean meal. Fat supplements partially replaced corn grain (Table 3 ). Calves were offered concentrate and chopped alfalfa hay ad libitum as mixture. Metabolizable energy of starter feeds was calculated according to NRC (2001). Calcium concentration was increased from $0.72 \%$ in the CON diet to $0.90 \%$ in the fat-supplemented diets on the grounds that fat supplementation has been shown to reduce the digestibility of dietary Ca (NRC, 2001). The calves received $4 \mathrm{~L}$ of whole milk/d from d 3 to 20 , $5 \mathrm{~L} / \mathrm{d}$ from d 21 to $25,6 \mathrm{~L} / \mathrm{d}$ from d 26 to 45 (twice daily), and $3 \mathrm{~L} / \mathrm{d}$ milk during morning feeding from $\mathrm{d}$ 46 to 49 of age. Water was also provided through the nipples. Finally, animals were weaned at $50 \mathrm{~d}$ of age and maintained on the study until $70 \mathrm{~d}$ of age.

\section{Measurements, Sample Collection, and Chemical and Biochemical Analysis}

Daily fecal scoring was performed in the morning $(0800 \mathrm{~h})$ as follows: $1=$ normal, $2=$ soft to loose, $3=$ loose to watery, $4=$ watery, mucous, slightly bloody, and $5=$ watery, mucous, and bloody. The amounts of starter diets offered and refused were recorded daily throughout the experiment. To determine apparent digestibility, fecal samples were obtained twice a day (in 
FAT SOURCES IN CALF STARTER

Table 1. Minimum and maximum temperature and humidity by month throughout the study

\begin{tabular}{lccccc}
\hline & \multicolumn{2}{c}{ Temperature, ${ }^{\circ} \mathrm{C}$} & & \multicolumn{2}{c}{ Humidity, \% } \\
\cline { 2 - 3 } \cline { 5 - 6 } Month & Minimum & Maximum & & Minimum & Maximum \\
\hline November 2014 & -6.6 & 19.8 & & 17 & 100 \\
December 2014 & -11.6 & 19.6 & & 15 & 99 \\
January 2015 & -12.0 & 21.8 & & 4 & 94 \\
February 2015 & -12.6 & 21.8 & & 7 & 98 \\
\hline
\end{tabular}

Table 2. Fatty acid composition (DM basis) of the fat supplements used in this experiment

\begin{tabular}{lcccc}
\hline & \multicolumn{4}{c}{ Fat source $^{1}$} \\
\cline { 2 - 5 } Fatty acid, \% & Palm fat & Soybean oil & Tallow & Fish oil \\
\hline C12:0 & 2.3 & - & - & - \\
C14:0 & 4.2 & 0.1 & 2.4 & - \\
C16:0 & 86.0 & 11.0 & 26.2 & 33.0 \\
C16:1 & - & 4.4 & 4.5 & - \\
C18:0 & 2.0 & 23.3 & 34.9 & 15.0 \\
C18:2 & 4.1 & 52.6 & 6.6 & 5.0 \\
C18:3 & - & 7.2 & 0.6 & 2.0 \\
C20:5 and C22:6 & - & - & - & 16.0 \\
\hline
\end{tabular}

${ }^{1}$ Palm fat (rumen protected, Energizer RP-10, IFFCO, Johor, Malaysia); soybean oil (Naz Industrial Vegetable Oil Co., Isfahan, Iran); tallow (Lador Fat, Ala Roghan Sepahan Co., Isfahan, Iran); fish oil (StrataG, Virtus Nutrition LLC, Corcoran, CA).

${ }^{2}$ Eicosapentaenoic acid (EPA; 20:5n-3) and docosahexaenoic acid (DHA; 22:6n-3).

Table 3. Ingredient and nutrients composition of starter diets supplemented without fat (control) or with different fat sources

\begin{tabular}{|c|c|c|c|c|c|}
\hline Item & \multicolumn{5}{|c|}{ Treatment $^{1}$} \\
\hline \multicolumn{6}{|l|}{ Ingredients, $\%$} \\
\hline Corn grain, cracked & 46.8 & 41.8 & 41.8 & 41.8 & 42.0 \\
\hline Barley grain, cracked & 14.2 & 14.2 & 14.2 & 14.2 & 14.2 \\
\hline Soybean meal, $45 \% \mathrm{CP}$ & 26.0 & 27.5 & 27.5 & 27.5 & 27.5 \\
\hline Fish oil Ca salt ${ }^{1}$ & - & - & - & - & 1.2 \\
\hline Calcium carbonate & 1.2 & 1.6 & 1.6 & 1.6 & 1.3 \\
\hline Sodium bicarbonate & 1.0 & 1.0 & 1.0 & 1.0 & 1.0 \\
\hline Vitamins and minerals premix ${ }^{2}$ & 0.5 & 0.5 & 0.5 & 0.5 & 0.5 \\
\hline Salt & 0.3 & 0.3 & 0.3 & 0.3 & 0.3 \\
\hline \multicolumn{6}{|l|}{ Nutrient composition } \\
\hline $\mathrm{P}, \% \mathrm{DM}$ & 0.42 & 0.40 & 0.40 & 0.40 & 0.40 \\
\hline Calculated $\mathrm{ME}{ }^{3} \mathrm{Mcal} / \mathrm{kg}$ of DM & 3.07 & 3.15 & 3.18 & 3.14 & 3.19 \\
\hline Calculated CP:ME ratio, $\mathrm{g}$ of $\mathrm{CP} / \mathrm{Mcal}$ of $\mathrm{ME}$ & 62.9 & 61.6 & 61.6 & 61.5 & 60.8 \\
\hline Calculated n-6:n-3 fatty acids ratio & 17.9 & 17.9 & 10.1 & 16.6 & 5.85 \\
\hline
\end{tabular}


the morning and in the afternoon) during 3 consecutive days (from d 68 to 70). Feed, refusal, and fecal samples were dried at $55^{\circ} \mathrm{C}$ in a forced-air oven, ground to pass a 1-mm screen in a Wiley mill (Ogaw Seiki Co., Ltd., Tokyo, Japan), and then mixed thoroughly. All samples were analyzed for CP (AOAC International, 2000), ash $\left(4 \mathrm{~h}\right.$ at $\left.550^{\circ} \mathrm{C}\right)$, ether extract (EE; AOAC International, 2000), and NDF using an Ankom ${ }^{200}$ fiber analyzer (Ankom Technology, Macedon, NY) and heat-stable $\alpha$-amylase according to the procedures described in Van Soest et al. (1991). Acid-insoluble ash was used as an internal marker to estimate the apparent total-tract digestibility of DM, CP, NDF and EE (Van Keulen and Young, 1977). Calves were weighed at the onset of the experiment and also every $10 \mathrm{~d}$ throughout the study period. Body length, heart girth, body barrel, withers height, and hip height measurements of the calves were recorded at 3 intervals (d 3, 50, and 70).

On d 35 and 70 of the study period, blood samples were collected from each calf in evacuated tubes (5 $\mathrm{mL} ; \mathrm{K}_{2}$ EDTA, Avapezeshk, Tehran, Iran) $3 \mathrm{~h}$ after the morning feeding. The samples were centrifuged $(1,500$ $\times g$ for $20 \mathrm{~min}$ at $20^{\circ} \mathrm{C}$ ), and the plasma obtained were stored at $-20^{\circ} \mathrm{C}$ until subsequent analysis. Plasma urea nitrogen (PUN), glucose, triacylglycerol (TAG), cholesterol, and high-density lipoprotein (HDL) concentrations were measured with a spectrophotometric autoanalyzer (UNICCO, 2100; Zistchemi Co., Tehran, Iran) using the commercially available clinical investigation kits (Parsazemun Co. Ltd., Karaj, Iran) according to the manufacturers' instructions.

Ruminal fluid ( $\mathrm{n}=7 /$ treatment) was obtained using a stomach tube $3 \mathrm{~h}$ after the morning feeding at d 35 and 70 of study. After the first 20-mL sample was discarded to minimize saliva contamination, rumen $\mathrm{pH}$ was immediately measured. A sample of the filtered ruminal fluid ( $4 \mathrm{~mL}$ ) was added to $1 \mathrm{~mL}$ of $25 \%$ metaphosphoric acid and sample was stored at $-20^{\circ} \mathrm{C}$ until VFA analysis. Individual VFA concentrations in the ruminal fluid were determined by GC (CP-9002; Chrompack, Middelburg, the Netherlands) using a silica-fused column (CP-Wax Chrompack Capillary Column; Varian, Palo Alto, CA). Helium was used as the carrier gas and oven initial and final temperatures were set at 55 and $195^{\circ} \mathrm{C}$, respectively. Detector and injector temperatures were set at $250^{\circ} \mathrm{C}$. Crotonic acid $(1: 7, \mathrm{vol} / \mathrm{vol})$ was used as the internal standard.

\section{Statistical Analysis}

Data collected were analyzed using the MIXED procedure of SAS (version 9.0, 2002, SAS Institute Inc., Cary, NC). Feed intake, ADG, feed efficiency, and fecal score data were analyzed separately for 3 discrete periods as preweaning (d 3-50 of the experiment), post weaning (d 50-70), and overall (d 3-70) periods. Variables with repeated measurements (intake, ADG, and feed efficiency) within the same calf were analyzed with the fixed effects of treatment, time of measurement (day), interaction between treatment and time, and sex of calf, as well as the random effect of calf nested within treatment. The time series covariance structure was modeled using 4 different covariance structures for each variable tested, and the compound symmetry was selected as the variance-covariance matrix structure on the basis of best fit according to Schwarz's Bayesian information criterion. Fecal score data were analyzed using a multivariable logistic mixed model (GLIMMIX procedure of SAS, version 9.3). Rumen fermentation parameters, plasma metabolites, BW, skeletal growth, and apparent nutrient digestibility data were analyzed with the same mixed-effects model described above but without the effect of time period (repeated measure). For BW and skeletal growth, the initial values were considered as covariates. Differences between means were separated using the Tukey test. Treatment differences with $P \leq 0.05$ were considered significant, and from $0.05<P \leq 0.10$ were designated as tendency.

\section{RESULTS}

\section{Weather and Diet Composition}

The average monthly temperatures recorded for Isfahan (east) in November, December, January, and February were $6.6,4.0,4.9$, and $4.6^{\circ} \mathrm{C}$, respectively (Table 1 ). The lowest and highest monthly temperatures were -12.6 and $21.8^{\circ} \mathrm{C}$, respectively, which occurred in February.

All diets were formulated to contain $20 \% \mathrm{CP}$, but assayed concentrations were lower $(\sim 0.56 \%)$ than the target CP concentration (Table 3). Dietary energy density was increased from 3.07 to $3.17 \mathrm{Mcal} / \mathrm{kg}$ of DM by replacing corn with fat supplements. The primary difference between the 4 fat-supplemented diets was in their FA composition (Table 2). The PLF was primarily in free FA form, and contained $85 \%$ of its FA as palmitic acid. Both SBO and TAL were TAG that may be hydrolyzed and biohydrogenated in rumen. Palmitic and stearic acids (SFA) accounted for $46 \%$ and oleic acid (MUFA) for $35 \%$ of the FA content of TAL. Sources of PUFA were the SBO that contained about $53 \%$ linoleic acid and $7 \% \alpha$-linolenic acid, and the calcium salt of fish oil containing $16 \%$ of $\mathrm{FA}$ as eicosapentaenoic acid and docosahexaenoic acid. The calculated n-6-to-n-3 FA ratio was altered neither in the TAL nor in the PLF diets, but it was decreased in the SBO and MIX diets (Table 3). 
Table 4. Intake, ADG, feed efficiency, fecal score, and apparent digestibility (postweaning) in Holstein calves fed starter diets supplemented without fat (control), or with different fat sources during the cold season

\begin{tabular}{|c|c|c|c|c|c|c|c|c|c|}
\hline \multirow[b]{2}{*}{ Item } & \multicolumn{5}{|c|}{ Treatment $^{1}$} & \multirow[b]{2}{*}{ SEM } & \multicolumn{3}{|c|}{$P$-value ${ }^{2}$} \\
\hline & $\mathrm{CON}$ & PLF & $\mathrm{SBO}$ & TAL & MIX & & $\mathrm{F}$ & $\mathrm{T}$ & $\mathrm{F} \times \mathrm{T}$ \\
\hline $3-50 \mathrm{~d}$ & $369^{\mathrm{ab}}$ & $432^{\mathrm{a}}$ & $418^{\mathrm{a}}$ & $384^{\mathrm{a}}$ & $276^{\mathrm{b}}$ & 38.0 & 0.04 & $<0.01$ & 0.01 \\
\hline $50-70 \mathrm{~d}$ & $2,194^{\mathrm{a}}$ & $2,295^{\mathrm{a}}$ & $2,243^{\mathrm{a}}$ & $2,170^{\mathrm{a}}$ & $1,856^{\mathrm{b}}$ & 95.1 & 0.02 & $<0.01$ & 0.50 \\
\hline $3-70 \mathrm{~d}$ & $888^{\mathrm{a}}$ & $958^{\mathrm{a}}$ & $939^{\mathrm{a}}$ & $894^{\mathrm{a}}$ & $727^{\mathrm{b}}$ & 48.1 & 0.01 & $<0.01$ & 0.01 \\
\hline \multicolumn{10}{|c|}{ Total DMI (milk + starter), g/d } \\
\hline $3-70 \mathrm{~d}$ & $1,307^{\mathrm{a}}$ & $1,378^{\mathrm{a}}$ & $1,359^{\mathrm{a}}$ & $1,314^{\mathrm{a}}$ & $1,147^{\mathrm{b}}$ & 48.5 & 0.01 & $<0.01$ & 0.24 \\
\hline \multicolumn{10}{|c|}{$\mathrm{ME}$ intake, Mcal/d } \\
\hline $3-50 \mathrm{~d}$ & $4.28^{\mathrm{ab}}$ & $4.52^{\mathrm{a}}$ & $4.48^{\mathrm{a}}$ & $4.36^{\mathrm{ab}}$ & $4.04^{\mathrm{b}}$ & 0.120 & 0.04 & $<0.01$ & 0.09 \\
\hline $50-70 \mathrm{~d}$ & $6.74^{\mathrm{ab}}$ & $7.23^{\mathrm{a}}$ & $7.13^{\mathrm{a}}$ & $6.81^{\mathrm{a}}$ & $5.92^{\mathrm{b}}$ & 0.029 & 0.02 & 0.03 & 0.67 \\
\hline $3-70 \mathrm{~d}$ & $4.98^{\mathrm{ab}}$ & $5.27^{\mathrm{a}}$ & $5.24^{\mathrm{a}}$ & $5.06^{\mathrm{a}}$ & $4.57^{\mathrm{b}}$ & 0.152 & 0.01 & $<0.01$ & 0.47 \\
\hline \multicolumn{10}{|l|}{$\mathrm{ADG}, \mathrm{g} / \mathrm{d}$} \\
\hline $3-50 \mathrm{~d}$ & 592 & 591 & 641 & 633 & 542 & 26.5 & 0.07 & $<0.01$ & $<0.01$ \\
\hline \multicolumn{10}{|c|}{ Feed efficiency, $\mathrm{kg}$ of ADG to $\mathrm{kg}$ of total DMI } \\
\hline $3-70 \mathrm{~d}$ & 0.552 & 0.530 & 0.582 & 0.580 & 0.550 & 0.015 & 0.07 & $<0.01$ & 0.16 \\
\hline \multicolumn{10}{|l|}{ Fecal score ${ }^{3}$} \\
\hline $3-35 \mathrm{~d}$ & 1.21 & 1.26 & 1.13 & 1.18 & 1.26 & 0.048 & 0.22 & $<0.01$ & 0.06 \\
\hline $35-70 \mathrm{~d}$ & 1.06 & 1.03 & 1.04 & 1.02 & 1.04 & 0.016 & 0.51 & $<0.01$ & 0.46 \\
\hline $3-70 \mathrm{~d}$ & 1.17 & 1.20 & 1.10 & 1.13 & 1.20 & 0.039 & 0.35 & $<0.01$ & 0.59 \\
\hline \multicolumn{10}{|c|}{ Apparent total-tract digestibility (d 68-70), \% } \\
\hline $\mathrm{DM}$ & 67.2 & 68.9 & 63.9 & 62.1 & 68.7 & 3.77 & 0.55 & - & - \\
\hline $\mathrm{NDF}$ & 51.6 & 48.4 & 44.7 & 43.5 & 43.4 & 3.93 & 0.39 & - & - \\
\hline $\mathrm{CP}$ & 67.4 & 67.9 & 64.7 & 64.0 & 68.6 & 3.93 & 0.39 & - & - \\
\hline Ether extract & 68.4 & 68.1 & 70.5 & 72.5 & 68.7 & 1.77 & 0.29 & - & - \\
\hline
\end{tabular}

${ }_{\mathrm{a}, \mathrm{b}}$ Means within a row with different superscripts differ $(P<0.05)$.

${ }^{1} \mathrm{CON}=$ control $($ no fat supplementation); PLF = palm fat (rumen protected, Energizer RP-10, IFFCO, Johor, Malaysia); SBO = soybean oil (Naz Industrial Vegetable Oil Co, Isfahan, Iran); TAL = tallow (Lador Fat, Ala Roghan Sepahan Co. Isfahan, Iran); MIX = mixture containing PLF, SBO, and fish oil (StrataG, Virtus Nutrition, LLC, Corcoran, CA).

${ }^{2} \mathrm{~F}=$ effect of fat sources; $\mathrm{T}=$ effect of time; $\mathrm{F} \times \mathrm{T}=$ interaction between fat and time.

${ }^{3}$ Fecal score system: $1=$ normal; $2=$ soft to loose; $3=$ loose to watery; 4 = watery, mucous, and slightly bloody; and $5=$ watery, mucous, and bloody.

\section{Performance and Fecal Score}

Starter intake, total DMI, ADG, feed efficiency, apparent digestibility, and fecal score are presented in Table 4. Calves fed the MIX diet had lower $(P<0.01)$ starter intake than those fed the CON during the preweaning and postweaning periods, whereas these same measures in calves fed the other fat-supplemented diets were similar to those of calves fed the CON diet. This showed that MIX supplementation $(P<0.01)$ reduced the calculated ME intake, whereas feeding the PLF, $\mathrm{SBO}$, or TAL diets tended $(P=0.08)$ to increase ME intake. Dietary fat sources had different effects on ADG during both the preweaning and postweaning periods $(P<0.01)$. In the overall period (d $3-70)$, greater ADG values were recorded for calves fed the SBO, TAL, PLF, and CON diets than for those fed MIX (Table 4). Moreover, ADG values tended to be lower in the CON $(P=0.10)$ and PLF $(P=0.09)$ diets versus the SBO diet from 3 to 70 d. Feed efficiency, calculated as kilograms of ADG per kilogram of DMI, tended $(P=0.07)$ to be greatest in calves fed SBO and TAL, intermediate in those fed CON and MIX, and lowest in those fed PLF. We found no dietary effects on preweaning and postweaning fecal score or on postweaning digestibility of nutrients (DM, CP, EE, and NDF).

\section{BW and Skeletal Growth}

The values for BW, hip height, wither height, body length, body barrel, and hip width are presented in Table 5. Body weights on d 50 (weaning) and 70 were lower in calves fed the MIX diet than in those fed the CON and other fat-supplemented diets. Body length, hip width, wither height, and hip height on d 50 and 70 were not affected by the treatments, except for the MIX treatment that tended $(P=0.08)$ to reduce body barrel on d 70 . 


\section{Ruminal Parameters}

Table 6 shows the values for ruminal $\mathrm{pH}$, ammonia, and total VFA concentrations as well as the proportions of individual VFA $3 \mathrm{~h}$ after feeding. Dietary treatments were found to have no effects on ruminal $\mathrm{pH}$, ammonia or total VFA concentrations. Moreover, no differences $(P>0.05)$ were observed among calves that received the CON diet and those that received the TAL, SBO, or PLF diets in terms of molar proportions of acetate, propionate, and butyrate. However, calves fed the MIX diet had the highest molar proportion of propionate and the lowest acetate-to-propionate ratio on $\mathrm{d} 35$ ( $P$ $=0.03)$.

\section{Blood Metabolites}

Table 7 presents the mean concentrations of glucose, PUN, TAG, cholesterol, and HDL. Moreover, calves fed the SBO, TAL, and MIX diets showed increased TAG concentrations but decreases were observed in those on the CON and PLF treatments. Dietary fat sources had no effects on plasma glucose, PUN, TAG, cholesterol, and HDL concentrations on $\mathrm{d} 35$. On d 70, however, plasma glucose concentration tended $(P=0.07)$ to be the highest in calves fed the SBO diet, intermediate in those fed the TAL and PLF diets, and the lowest in those fed the CON and MIX diets. Calves fed SBO, TAL, or PLF had higher total cholesterol and HDL cholesterol concentrations than those fed either the
CON or the MIX diet $(P=0.01)$. Moreover, fat supplementation tended $(P=0.08)$ to increase postweaning plasma TAG concentration.

\section{DISCUSSION}

Thermogenesis due to the mobilization of stored lipids in brown adipose tissue is an important mechanism of heat production in newborn mammals (Smith et al., 2004). Compared with adults, however, young calves are expected to suffer greater thermal stresses in winter, because their heat increment production from fermentation and chewing and heat conservation mechanism (thin skin and small quantity of subcutaneous fat) are not fully developed. Moreover, calves have a large surface area to volume, but limited body energy reserves. During the current study period, the average temperature $\left(5.0^{\circ} \mathrm{C}\right)$ was below the lower critical temperature $\left(15^{\circ} \mathrm{C}\right)$ for young calves (NRC, 2001). When the ambient temperature is $5^{\circ} \mathrm{C}$, maintenance energy requirements increase by $40 \%$ for calves from birth until the age of $3 \mathrm{wk}$, and $13 \%$ for calves $>3 \mathrm{wk}$ of age (NRC, 2001). In more mature animals, fat can be mobilized to make up for this energy deficit; young calves, however, have about $3 \%$ body fat reserves and excess energy must be supplied to avoid the negative consequences (Davis and Drackley, 1998).

We hypothesized that providing fat supplements at the typical inclusion rates might not limit DMI during cold weather and results in increased energy availability

Table 5. Body weight measurements in Holstein calves fed starter diets supplemented without fat (control), or with different fat sources during the cold season

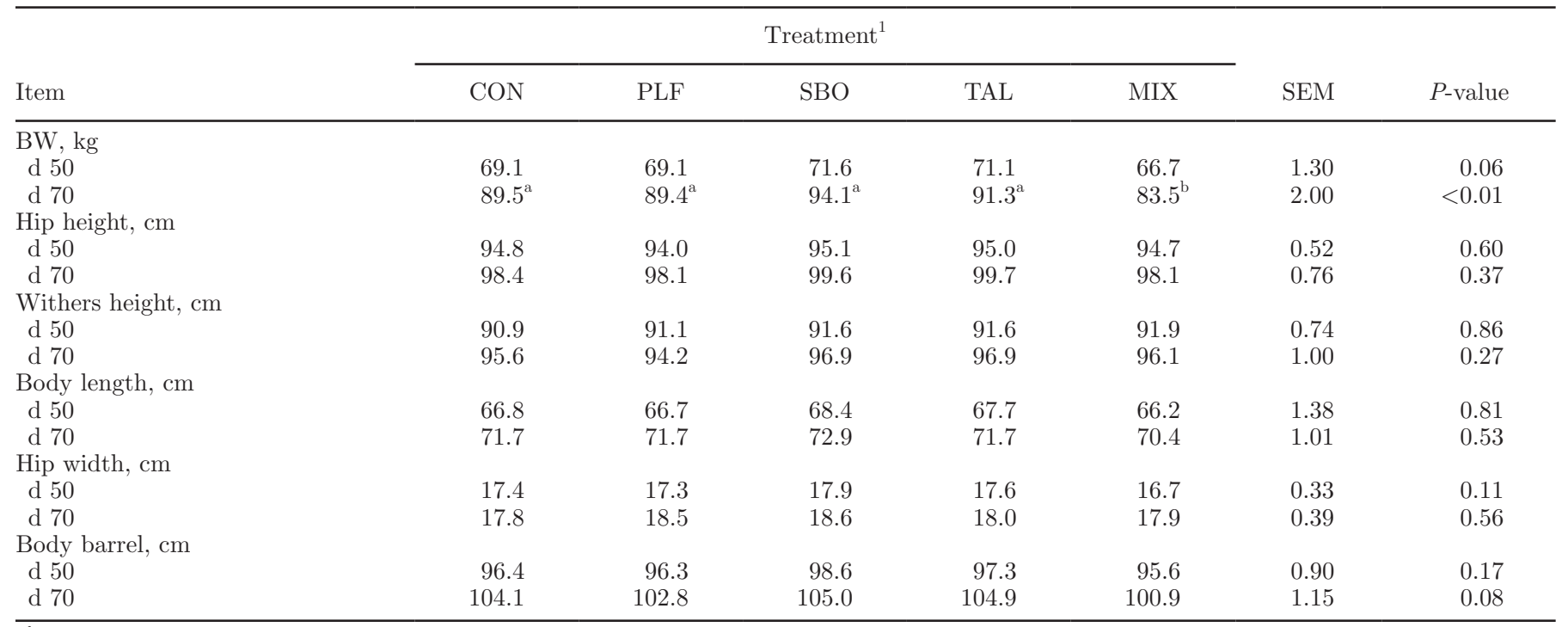

a,b Means within a row with different superscripts differ $(P<0.05)$.

${ }^{1} \mathrm{CON}=$ control (no fat supplementation); PLF = palm fat (rumen protected, Energizer RP-10, IFFCO, Johor, Malaysia); SBO = soybean oil (Naz Industrial Vegetable Oil Co., Isfahan, Iran); TAL = tallow (Lador Fat, Ala Roghan Sepahan Co., Isfahan, Iran); MIX = mixture containing PLF, SBO, and fish oil (StrataG, Virtus Nutrition LLC, Corcoran, CA). 
Table 6. Ruminal pH, ammonia, and VFA concentrations in Holstein calves fed starter diets supplemented without fat (control), or with different fat sources during the cold season

\begin{tabular}{|c|c|c|c|c|c|c|c|}
\hline \multirow[b]{2}{*}{ Item } & \multicolumn{5}{|c|}{ Treatment $^{1}$} & \multirow[b]{2}{*}{ SEM } & \multirow[b]{2}{*}{$P$-value } \\
\hline & $\mathrm{CON}$ & PLF & SBO & TAL & MIX & & \\
\hline d 35 & 5.40 & 5.44 & 5.40 & 5.71 & 5.75 & 0.185 & 0.48 \\
\hline d 70 & 5.73 & 5.87 & 5.91 & 6.00 & 5.73 & 0.218 & 0.86 \\
\hline \multicolumn{8}{|c|}{ Rumen ammonia, mg/dL } \\
\hline d 35 & 13.3 & 16.8 & 15.3 & 14.0 & 17.3 & 1.92 & 0.52 \\
\hline d 35 & 85.7 & 90.8 & 88.4 & 91.6 & 83.1 & 12.48 & 0.98 \\
\hline d 70 & 128.9 & 119.7 & 127.7 & 119.1 & 107.1 & 9.17 & 0.47 \\
\hline \multicolumn{8}{|c|}{ Acetate, $\mathrm{mmol} / 100 \mathrm{mmol}$} \\
\hline d 35 & 49.2 & 47.0 & 48.8 & 50.3 & 45.6 & 1.82 & 0.44 \\
\hline d 70 & 48.1 & 47.0 & 47.2 & 49.7 & 45.0 & 1.45 & 0.30 \\
\hline \multicolumn{8}{|c|}{ Propionate, $\mathrm{mmol} / 100 \mathrm{mmol}$} \\
\hline d 35 & $31.7^{\mathrm{b}}$ & $32.4^{\mathrm{b}}$ & $34.8^{\mathrm{ab}}$ & $34.8^{\mathrm{ab}}$ & $37.6^{\mathrm{a}}$ & 1.72 & 0.05 \\
\hline d 35 & $1.57^{\mathrm{a}}$ & $1.50^{\mathrm{ab}}$ & $1.41^{\mathrm{ab}}$ & $1.45^{\mathrm{ab}}$ & $1.22^{\mathrm{a}}$ & 0.102 & 0.03 \\
\hline d 70 & 1.28 & 1.23 & 1.19 & 1.40 & 1.06 & 0.112 & 0.22 \\
\hline
\end{tabular}

${ }_{\mathrm{a}, \mathrm{b}}$ Means within a row with different superscripts differ $(P<0.05)$.

${ }^{1} \mathrm{CON}=$ control (no fat supplementation); PLF = palm fat (rumen protected, Energizer RP-10, IFFCO, Johor, Malaysia); SBO = soybean oil (Naz Industrial Vegetable Oil Co., Isfahan, Iran); TAL = tallow (Lador Fat, Ala Roghan Sepahan Co., Isfahan, Iran); MIX = mixture containing PLF, SBO, and fish oil (StrataG, Virtus Nutrition LLC, Corcoran, CA).

for growth. In none of the preweaning, postweaning, or overall periods did the CON group exhibit any differences from the TAL, SBO, or PLF ones with respect to DMI; these results are consistent with those obtained by Garcia et al. (2014) and Araujo et al. (2014), but inconsistent with those reported by Fallon et al. (1986), Hill et al. (2015), and Kazemi-Bonchenari et al. (2016). The reason for the different responses observed in different studies could be due to differences in the methods and levels of milk feeding, types of solid feed, types and levels of fat supplemented, calf housing and management, and climate. Our data indicate that young calves increase

Table 7. Plasma metabolites in Holstein calves fed starter diets supplemented without fat (control), or with different fat sources during the cold season

\begin{tabular}{|c|c|c|c|c|c|c|c|}
\hline Item & \multicolumn{5}{|c|}{ Treatment $^{1}$} & SEM & $P$-value \\
\hline \multicolumn{8}{|c|}{ Glucose, $\mathrm{mg} / \mathrm{dL}$} \\
\hline d 70 & 87.2 & 94.3 & 102 & 97.4 & 84.5 & 4.53 & 0.07 \\
\hline \multicolumn{8}{|c|}{ Urea nitrogen, mg/dL } \\
\hline d 35 & 17.8 & 17.8 & 18.5 & 21.2 & 20.5 & 1.60 & 0.48 \\
\hline d 35 & 25.3 & 24.8 & 22.0 & 24.6 & 21.5 & 3.12 & 0.85 \\
\hline d 70 & 19.5 & 22.4 & 29.5 & 29.0 & 26.2 & 2.83 & 0.08 \\
\hline \multicolumn{8}{|c|}{ Cholesterol, mg/dL } \\
\hline d 35 & 124 & 126 & 115 & 117 & 117 & 10.8 & 0.92 \\
\hline d 70 & $68.0^{\mathrm{b}}$ & $96.6^{\mathrm{a}}$ & $81.8^{\mathrm{ab}}$ & $81.8^{\mathrm{ab}}$ & $66.2^{\mathrm{b}}$ & 6.77 & 0.01 \\
\hline \multicolumn{8}{|c|}{ High-density lipoprotein, mg/dL } \\
\hline d 35 & 92.5 & 87.9 & 80.0 & 90.0 & 82.9 & 5.04 & 0.53 \\
\hline
\end{tabular}

${ }^{\mathrm{a}-\mathrm{c}}$ Means within a row with different superscripts differ $(P<0.05)$.

${ }^{1} \mathrm{CON}=$ control $($ no fat supplementation) $\mathrm{PLF}=$ palm fat (rumen protected, Energizer RP-10, IFFCO, Johor, Malaysia); SBO = soybean oil (Naz Industrial Vegetable Oil Co., Isfahan, Iran); TAL = tallow (Lador Fat, Ala Roghan Sepahan Co., Isfahan, Iran); MIX = mixture containing PLF, SBO, and fish oil (StrataG, Virtus Nutrition LLC, Corcoran, CA). 
their energy intake during cold stress, and feed intake is not limited by metabolic factors as fat supplements $(3 \%)$ are fed. Holt (2014) reported that calves raised in winter months consumed more calf starter than did those born in other months. In dairy cows, fat supplements differ markedly in their effects on DMI; generally UFA supplements tend to reduce DMI, whereas SFA have slight effects on DMI (Palmquist, 2010). In the current study, no such differences were observed in DMI and digestibility among calves receiving the fat supplements containing primarily SFA (PLF), MUFA (TAL), or PUFA (SBO). However, feeding the supplemental MIX containing fish oil led to reduced eating time (data not shown) and DMI during the treatment period. Karcher et al. (2014) observed no differences in starter or milk replacer intake by calves before $28 \mathrm{~d}$ of age, when fish oil was added to milk replacer. In fact, starter intake was comparatively low $(\sim 100 \mathrm{~g} / \mathrm{d})$ in that study. Hill et al. (2015) reported that calves fed starter supplemented with SBO had reduced starter intake and digestibility, but such responses were not observed when TAL was added. Araujo et al. (2014) did not find any differences in starter consumption between calves receiving no added fat and those supplemented with full-fat soybean at high inclusion rates (37\%). Montoro and Bach (2012) observed that calves preferentially consumed a diet with $29 \% \mathrm{CP}$ and $6 \%$ fat, suggesting that calves might prefer a diet higher in fat content than the typical starter feeds. In the current study, the supplemented diets contained around 6\% fat in DM.

In the current study, the calves receiving the TAL and PLF diets recorded ADG similar to those of the CON calves despite their higher ME intake. However, calves receiving the SBO gained $9 \%$ more than the CON group in the overall period (d 3-70). In addition, gain-to-feed ratio was $10 \%$ greater in calves fed SBO as compared with PLF. Araujo et al. (2014) showed that starters with soybeans supported additional ADG when milk replacer was fed at approximately 0.69 but not at $0.46 \mathrm{~kg}$ of DM daily. In our study, the daily amount of whole milk (DM basis) consumed was approximately $0.63 \mathrm{~kg} / \mathrm{d}$. The NRC (2001) recommends dietary levels of $18 \% \mathrm{CP}, 13 \% \mathrm{NDF}, 3 \% \mathrm{EE}$, and 3.28 $\mathrm{Mcal} / \mathrm{kg}$ of ME for the starter feed, with approximately $55 \mathrm{~g}$ of $\mathrm{CP} / \mathrm{Mcal}$ of ME. However, starter diets are fed with typically higher levels of $\mathrm{CP}$ (e.g., $\geq 20 \%$ ) or fiber content (Maktabi et al., 2016) and a lower CP-to$\mathrm{ME}$ ratio than the recommended concentrations (NRC, 2001). Fat supplementation could, therefore, increase calories, optimize the $\mathrm{CP}$-to-ME ratio, and thereby might affect growth performance. The diets used in the current study contained $10 \%$ alfalfa hay and their CPto-energy ratios decreased from 63 to $61 \mathrm{~g}$ of $\mathrm{CP} / \mathrm{Mcal}$ of ME by fat supplementation. Further research may be needed to determine the effects of nutrient levels and their interactions (e.g., energy or fat, protein, and fiber sources) in starter feeds.

Feeding SBO and TAL increased the concentrations of blood lipids, such as cholesterol, TAG, and HDL, and PLF increased blood concentrations of cholesterol and HDL at postweaning. In preruminant calves, high-fat diets reportedly stimulated the secretion of TAG-rich lipoproteins (such as chylomicrons) as well as HDL (Piot et al., 2000). Moreover, cholesterol is synthesized primarily from products of lipid metabolism in the liver of preruminant calves (Drackley, 2005). Feeding MIX containing fish oil was observed to reduce blood concentrations of cholesterol and HDL, but not that of TAG. Research in humans, however, shows that eicosapentaenoic acid and docosahexaenoic acid supplements lower the blood TAG, but produce no change in the overall HDL concentration (Anil, 2007). The differences between the responses observed in the current study and those reported by Anil (2007) might be attributed either to differences between the species in terms of their lipogenesis (Laliotis et al., 2010) or the different types of supplements used (MIX containing SBO and PLF as well).

The preferred substrate as energy source for skeletal (resting) and heart muscles, white and brown adipose tissues, and liver is FA (Berg et al., 2002). Utilization of FA as a main energy source may spare the use of other substrates, such as glucose or AA, so that they can be available for other uses. Therefore, supplemental fat might reduce the amounts of glucose and AA catabolized for energy, resulting in a greater proportion of dietary AA available for lean tissue growth in conditions below the thermal neutral zone. Although all the fat supplements used in our study were observed to increase blood lipids, only the SBO led to a greater glucose concentration than the CON diet (d 70). Garcia et al. (2014) showed that plasma glucose and IGF-I were not affected by supplemental fat, but partially replacing coconut oil with porcine lard (high linoleic acid) in milk replacer increased linoleic intake, and resulted in increased plasma concentrations of glucose and IGFI. Similarly, greater plasma concentrations of linoleic acid and glucose were recorded in beef calves suckling cows that had received diets containing high-linoleate safflower seeds (11.8\% of dietary DM) compared with those fed no oilseeds (Lake et al., 2006).

The increased growth rate of calves supplemented with SBO, rather than other fat sources, might also be related to differences in FA composition. Vegetable oils, which are rich in PUFA, have been used to prevent deficiency or to satisfy the requirements of linoleic and $\alpha$-linolenic acids, especially during stressful conditions in preruminant calves (Jenkins and Kramer, 
1986). Allen et al. (1985) found that adding linoleic acid to culture medium markedly improved fusion of muscle satellite cells. Garcia et al. (2014) concluded that linoleic acid enhanced cell growth in preweaned calves without the mediation of IGF-I or stimulation of IGF-I synthesis. Santos et al. (2013) reported that calves fed a milk replacer enriched with a high, rather than a low, linoleic acid content not only gained more BW by $3 \mathrm{~kg}$, but produced an additional 1,000 $\mathrm{kg}$ of 305-d mature-equivalent milk as well. In most studies on the effects of dietary essential FA supplements on young calves, milk replacer was used as the liquid feed (Hill et al., 2009, 2015; Araujo et al., 2014; Karcher et al., 2014). Unsaturated FA present in liquid feeds are not biohydrogenated as milk bypasses the rumen via the esophageal groove; however, whole milk fat is quite different from those used in milk replacer formulations. In fact, whole-fat cow milk has a very low linoleic acid content, but a more favorable linoleic acidto- $\alpha$-linolenic ratio (Michaelsen et al., 2007). Additionally, typical starter diets based on corn and soybean meal are low in linolenic acid (Hill et al., 2009). The SBO contained both essential linoleic and $\alpha$-linolenic acids, and the ratio of linoleic acid to $\alpha$-linolenic acid decreased from about 18 to 10 as a result of adding $3 \%$ SBO. An ideal ratio of n- 6 to n- 3 FA in the human infant diet is estimated to be 6:1 (Klein, 2002). Leskanich and Noble (1999) suggested a 10:1 ratio of C18:2 to C18:3 for pigs based on a review of the literature. For dairy calves, no recommended dietary allowance of linoleic or $\alpha$-linolenic acid exists. Adult cattle have the capacity to retain the essential FA very efficiently and are capable of surviving on much lower essential FA intakes than nonruminants, which is due to their ability to incorporate a large part of linoleic acid into phospholipids and cholesterol esters, rather than nonesterified FA and TAG (Palmquist, 2010). However, not only is such information presently unavailable, but the extent of the biohydrogenation process that transforms PUFA profile in preruminants is unknown as well. As calves get older and the rumen develops, the microbes in the rumen presumably biohydrogenate the dietary essential FA.

In the present study, growth performance was found to be depressed in calves supplemented with MIX containing fish oil; however, adding MIX supplement had no effect on feed efficiency. Karcher et al. (2014) and Hill et al. (2015) reported that FA C20:5 and C22:6 of fish oil did not have the same effects as C18:3 at improving ADG. Feeding different fat sources did not affect ruminal $\mathrm{pH}$, ammonia or total VFA concentration, whereas feeding MIX increased the molar concentration of propionate and reduced the acetate-to-propionate ratio. To the best of our knowledge, the present study is the first of its kind to examine the effects of different fat sources on rumen fermentation parameters in dairy calves. Such changes in VFA molar proportion may be a reflection of changes in the amount of starter consumed or microbial metabolic activity. This finding is in line with the results reported in Shingfield et al. (2012), who studied mature cattle and reported that cows on a diet with a high fish oil supplement (about 1.5\% of the diet DM) had a greater rumen molar propionate proportion than those on a diet with a lower supplementation. The increased proportion of propionate and decreased acetate-to-propionate ratio may be a potential cause of decreased DMI by calves fed MIX.

Calves on all experimental diets had similar fecal scores and digestibility during the study. Hill et al. (2015) reported that fat digestibility of calves fed TAL was greater than that of the CON, but fat digestibility of SBO and the CON was not different. Araujo et al. (2014) reported a higher fat digestibility in their highfat soybean treatment than that in their low-fat one.

\section{CONCLUSIONS}

Feeding starter diet with fat content higher than $3 \%$ has been discouraged mainly due to the reduced voluntary starter intake, which diminishes the energy intake and rumen development in calves. However, supplementation with fat may be beneficial when feeding a highprotein or -fiber starter diet or under the effects of cold stress. Moreover, whole milk is poor in linoleic acid, and typical starters given to the young calf are also low in linolenic or eicosapentaenoic and docosahexaenoic acids. Results from the current study demonstrate a differential effect of type of FA on the performance of dairy calves during cold season. Including 3\% TAL, PLF, or SBO tended to increase ME intake; however, feeding PLF decreased feed efficiency and feeding TAL was not advantageous for calf growth. Increasing intake of linoleic and $\alpha$-linolenic acids by feeding 3\% SBO tended to enhance not only blood glucose and lipid concentrations, but also growth performance. On the other hand, supplementing MIX containing Ca salt of fish oil was observed to increase rumen molar proportion of propionate, but depressed both starter intake and ADG without affecting feed efficiency.

\section{ACKNOWLEDGMENTS}

The authors extend their gratitude to the staff (J. Jalilnejad, A. Khamesi, and H. Beiranvand) at FKA Dairy Farm (Isfahan, Iran) for their assistance in field data collection. The Ala Roghan Sepahan Co. (Isfahan, Iran) also deserve our thanks for supplying TAL used in this study. Isfahan University of Technology is 
also acknowledged for their support. Finally, Ezzatollah Roustazadeh from the English Language Center, Isfahan University of Technology, is acknowledged for having edited the final English manuscript.

\section{REFERENCES}

Allen, R. E., L. S. Luiten, and M. V. Dodson. 1985. Effect of insulin and linoleic acid on satellite cell differentiation. J. Anim. Sci. 60:1571-1579.

Anil, E. 2007. The impact of EPA and DHA on blood lipids and lipoprotein metabolism: Influence of apoE genotype. Proc. Nutr. Soc. 66:60-68.

AOAC International. 2000. Official Methods of Analysis. Vol. 1. 17th ed. AOAC International, Arlington, VA.

Araujo, G., M. Terré, and A. Bach. 2014. Interaction between milk allowance and fat content of the starter feed on performance of Holstein calves. J. Dairy Sci. 97:6511-6518.

Bach, A. 2012. Ruminant nutrition symposium: Optimizing performance of the offspring: Nourishing and managing the dam and postnatal calf for optimal lactation, reproduction, and immunity. J. Anim. Sci. 90:1835-1845.

Berg, J. M., J. L. Tymoczko, and L. Stryer. 2002. Biochemistry. 5th ed. W H Freeman, New York, NY.

Davis, C. D., and J. K. Drackley. 1998. The Development, Nutrition and Management of the Young Calf. Iowa State University Press, Ames.

Drackley, J. K. 2005. Interorgan lipid and fatty acid metabolism in growing ruminants. Pages 323-350 in Biology of Metabolism in Growing Animals. D. G. Burrin and H. J. Mersmann, ed. Elsevier Limited, Edinburgh, UK.

Fallon, R. J., P. E. V. Williams, and G. M. Innes. 1986. The effects on feed intake, growth and digestibility of nutrients of including calcium soaps of fat in diets for young calves. Anim. Feed Sci. Technol. 12:103-115.

Garcia, M., L. F. Greco, M. G. Favoreto, R. S. Marsola, D. Wang, J. H. Shin, E. Block, W. W. Thatcher, J. E. P. Santos, and C. R. Staples. 2014. Effect of supplementing essential fatty acids to pregnant nonlactating Holstein cows and their preweaned calves on calf performance, immune response, and health. J. Dairy Sci. 97:5045-5064.

Gelsinger, S. L., A. J. Heinrichs, and C. M. Jones. 2016. A metaanalysis of the effects of preweaned calf nutrition and growth on first-lactation performance. J. Dairy Sci. 99:6206-6214.

Hill, T. M., H. G. Bateman, J. M. Aldrich, J. D. Quigley, and R. L. Schlotterbeck. 2015. Inclusion of tallow and soybean oil to calf starters fed to dairy calves from birth to four months of age on calf performance and digestion. J. Dairy Sci. 98:4882-4888.

Hill, T. M., H. G. Bateman II, J. M. Aldrich, and R. L. Schlotterbeck. 2009. Effects of changing the essential and functional fatty acid intake of dairy calves. J. Dairy Sci. 92:670-676.

Hill, T. M., H. G. Bateman II, J. M. Aldrich, and R. L. Schlotterbeck. 2011. Impact of various fatty acids on dairy calf performance. Prof. Anim. Sci. 27:167-175.

Holt, S. D. 2014. Ambient temperature, calf intakes, and weight gains on preweaned dairy calves. MS thesis. Animal, Dairy, and Veterinary Sciences, Utah State University, Logan. Accessed Jun. 10, 2014. http://digitalcommons.usu.edu/etd/2324.

Jaster, E. H., G. C. McCoy, N. Spanski, and T. Tomkins. 1992. Effect of extra energy as fat or milk replacer solids in diets of young dairy calves on growth during cold weather. J. Dairy Sci. 75:2524-2531.

Jenkins, K. J., and J. K. G. Kramer. 1986. Influence of low linoleic and linolenic acids in milk replacer on calf performance and lipids in blood plasma, heart, and liver. J. Dairy Sci. 69:1374-1386.
Karcher, E. L., T. M. Hill, H. G. Bateman, R. L. Schlotterbeck, N. Vito, L. M. Sordillo, and M. J. VandeHaar. 2014. Comparison of supplementation of $\mathrm{n}-3$ fatty acids from fish and flax oil on cytokine gene expression and growth of milk-fed Holstein calves. J. Dairy Sci. 97:2329-2337.

Kazemi-Bonchenari, M., M. Mirzaei, M. Jahani-Moghadam, A. Soltani, E. Mahjoubi, and R. A. Patton. 2016. Interactions between levels of heat-treated soybean meal and prilled fat on growth, rumen fermentation, and blood metabolites of Holstein calves. J. Anim. Sci. 94:4267-4275. https://doi.org/10.2527/jas.2016-0514.

Klein, C. J., ed. 2002. Nutrient requirements for preterm infant formulas. J. Nutr. 132:1395S-1577S.

Lake, S. L., E. J. Scholljegerdes, D. M. Hallford, G. E. Moss, D. C Rule, and B. W. Hess. 2006. Effects of body condition score at parturition and postpartum supplemental fat effects on metabolite and hormone concentrations of beef cows and their suckling calves. J. Anim. Sci. 84:1038-1047.

Laliotis, G. P., I. Bizelis, and E. Rogdakis. 2010. Comparative approach of the de novo fatty acid synthesis (lipogenesis) between ruminant and non ruminant mammalian species: from biochemical level to the main regulatory lipogenic genes. Curr. Genomics 11:168-183.

Leskanich, C. O., and R. C. Noble. 1999. The comparative roles of polyunsaturated fatty acids in pig neonatal development. Br. J. Nutr. 81:87-106.

Maktabi, H., E. Ghasemi, and M. Khorvash. 2016. Effects of substituting grain with forage or nonforage fiber source on growth performance, rumen fermentation, and chewing activity of dairy calves. Anim. Feed Sci. Technol. 221:70-78.

Michaelsen, K. F., C. Hoppe, L. Lauritzen, and C. Mølgaard. 2007. Whole cow's milk: Why, what and when? Pages 201-219 in Issues in Complementary Feeding, Vol. 60. Karger Publishers. Basel, Switzerland.

Montoro, C., and A. Bach. 2012. Voluntary selection of starter feed ingredients offered separately to nursing calves. Livest. Sci. 149:6269 .

NRC. 2001. Nutrient Requirements of Dairy Cattle. 7th rev. ed. Natl. Acad. Sci., Washington, DC.

Palmquist, D. L. 2010. Essential fatty acids in ruminant diets. Pages 127-141 in Proceedings of the 21nd Annual Ruminant Nutrition Symposium. February 2-3, 2010. Gainesville, FL.

Piot, C., J. Hocquette, P. Herpin, J. H. Veerkamp, and D. Bauchart. 2000. Dietary coconut oil affects more lipoprotein lipase activity than the mitochondria oxidative capacities in muscles of preruminant calves. J. Nutr. Biochem. 11:231-238.

Santos, J. E., L. F. Greco, M. Garcia, W. W. Thatcher, and C. R. Staples. 2013. The role of specific fatty acids on dairy cattle performance and fertility. Florida Ruminant Nutrition Symposium.

Shingfield, K. J., P. Kairenius, A. Ärölä, D. Paillard, S. Muetzel, S Ahvenjärvi, A. Vanhatalo, P. Huhtanen, V. Toivonen, J. M. Griinari, and R. J. Wallace. 2012. Dietary fish oil supplements modify ruminal biohydrogenation, alter the flow of fatty acids at the omasum, and induce changes in the ruminal Butyrivibrio population in lactating cows. J. Nutr. 142:1437-1448.

Smith, S. B., G. E. Carstens, R. D. Randel, H. J. Mersmann, and D. K. Lunt. 2004. Brown adipose tissue development and metabolism in ruminants. J. Anim. Sci. 82:942-954.

Van Keulen, V., and B. H. Young. 1977. Evaluation of acid-insoluble ash as natural marker in ruminant digestibility studies. J. Anim. Sci. 26:119-135.

Van Soest, P. J., J. B. Robertson, and B. A. Lewis. 1991. Methods for dietary fiber, neutral detergent fiber, and nonstarch polysaccharides in relation to animal nutrition. J. Dairy Sci. 74:3583-3597. 